\title{
Frequency of Vitamin D Deficiency in Newly Diagnosed Type 2 Diabetes Mellitus Patients
}

\author{
Zara-tul-ain Bashir ${ }^{1, *}$, Huma Amjad², Syed Tanveer Abbas Gilani ${ }^{3}$, Amjad khan ${ }^{4}$, Syeda Urooj Riaz \\ ${ }^{1}$ Pakistan Navy Ship (PNS) Shifa Hospital, Karachi, Pakistan. \\ ${ }^{2}$ Combined Military Hospital (CMH), Abbottabad, Pakistan. \\ ${ }^{3}$ Combined Military Hospital (CMH), Bahawalnagar, Pakistan. \\ ${ }^{4}$ Pakistan Military Academy Hospital, Kakul Abbottabad, Pakistan. \\ ${ }^{5}$ Jinnah Medical and Dental Hospital, Karachi, Pakistan.
}

Abstract: Objective: To determine the frequency of vitamin D deficiency in newly diagnosed patients of type 2 diabetes mellitus.

Study Design: Prospective case control study.

Place and Duration of Study: Department of medicine, Pakistan Navy Ship (PNS) Shifa Hospital Karachi from January to December 2015.

Materials and Methods: A total of 302 study subjects were selected, out of which 151 healthy controls while 151 patients included in the study were newly diagnosed type-2 diabetes mellitus with non-probability, consecutive sampling at medical Out Patient Department (OPD) of PNS Shifa Karachi. All controls and newly diagnosed type-2 diabetics were tested for fasting plasma glucose, HbA1C and 25 hydroxycholecalciferol $\left(25(\mathrm{OH}) \mathrm{D}_{3} /\right.$ vitamin $\left.\mathrm{D}\right)$ levels in pathology laboratory of PNS Shifa Hospital. Patients having serum level of 25(OH) $\mathrm{D}_{3}<25 \mathrm{nmol} / \mathrm{L}$ was considered as having vitamin $\mathrm{D}$ deficiency.

Results: Out of total 302 subjects, vitamin D levels of $36 \pm 19 \mathrm{nmol} / \mathrm{L}$ in newly diagnosed type $2 \mathrm{DM}$ cases and of $65 \pm 31 \mathrm{nmol} / \mathrm{L}$ in controls of similar age groups and gender were found significantly lower in newly diagnosed type $2 \mathrm{DM}$. Vitamin D deficiency was found in 58 ( $38.4 \%$ ) cases and $13(8.6 \%)$ in controls. In 151 newly diagnosed patients of type 2 Diabetes, 73 (48 \%) were males and 78 (52\%) were females with mean age of $53.7 \pm 8.7$ years in both gender. In cases, mean and SD of fasting plasma glucose was $9.2 \pm 1.5 \mathrm{mmol} / \mathrm{L}, \mathrm{HbA1C} 9.4 \pm 1.4 \%$ and serum $25(\mathrm{OH}) \mathrm{D}_{3} 36 \pm 19 \mathrm{nmol} / \mathrm{L}$. In cases, low vitamin $\mathrm{D}$ levels in different age groups and gender was found significant with advancing age predominantly in females. Significant correlation was found between hyperglycemia (HbA1C) and vitamin D deficiency (p-value $<0.001$ ).

Conclusion: Higher frequency of vitamin D deficiency was found among patients newly diagnosed as diabetes mellitus type-2 with advancing age especially in females. Vitamin D levels were inversely related to hyperglycemia. Considering such high frequency, screening of diabetic patients for vitamin D deficiency would be beneficial.

Keywords: Type 2 diabetes mellitus, Vitamin D deficiency, Frequency, Hyperglycemia, Vitamin D receptor, Vitamin D binding protein.

\section{INTRODUCTION}

Type 2 Diabetes Mellitus (DM) is considered as one of the major public health problem resulting in premature mortality and morbidity [1]. Similarly, low Vitamin D levels constitute a largely unrecognized problem in many populations and its global prevalence has been estimated from 30 to $87 \%$ [2]. DM is a metabolic disease which can affect multiorgans in the body and recently vitamin $\mathrm{D}$ has aroused widespread interest in the pathogenesis of DM. Over the last five years, a number of large observational studies have suggested an association between DM type-2 and vitamin D deficiency [3,4] . Vitamin $\mathrm{D}$ levels have been documented to have significant inverse relationship with hyperglycemia [5]. Data from various

*Address correspondence to this author at the Pakistan Navy Ship (PNS)

Shifa Hospital, Karachi, Pakistan. E-mail: zara_malik08@hotmail.com studies on different populations regarding frequency of vitamin D deficiency in newly diagnosed cases of DM type-2 is showing a significant variation of $30 \%$ to $70 \%[6,7]$.

Vitamin D has a well-known role in calcium homeostasis and bone metabolism. The suboptimal levels of vitamin D may contribute to many conditions including rickets, osteomalacia, osteoporosis, falls and fractures. In addition, epidemiologic observations have associated low vitamin D status with an increased risk of non-musculoskeletal diseases, such as cancer, multiple sclerosis and cardiovascular diseases apart from being a risk for developing DM and diabetic complications $[8,9]$.

Over many years, links between vitamin D status and diabetes mellitus have been identified. As early as the 1980s [10], it was shown that vitamin D deficiency in rodents and rabbits 
inhibits pancreatic insulin secretion, indicating that vitamin D is essential for the function of the endocrine pancreas. Later, the connection between vitamin $\mathrm{D}$ and diabetes was reinforced by the discovery of the VDR (Vitamin D Receptor) and DBP (Vitamin D Binding Protein) in pancreatic tissue (more specifically in the insulin-producing b cells) and also in various cell types of the immune system. Thus, vitamin D has been proposed as a possible therapeutic agent in the prevention and treatment of T1D and T2D [11].

Vitamin D status is defined by measuring the level of 25 hydroxy-cholecalciferol $\left[25(\mathrm{OH}) \mathrm{D}_{3}\right]$ in the blood owing to its longer half-life in plasma. There are different views regarding recommended levels of $25(\mathrm{OH}) \mathrm{D}_{3}$, however in latest reviews it has been suggested that a serum concentration of less than $25 \mathrm{nmol} / \mathrm{L}$ must be considered as vitamin D deficiency, having varied musculoskeletal and systemic effects. The aim of our study is to find out frequency of vitamin D deficiency in newly diagnosed patients of type $2 \mathrm{DM}$ in our setup in comparison with healthy age and gender matched controls. This study will clarify the variations in our targeted population and also record its frequency in newly diagnosed type $2 \mathrm{DM}$ cases and its correlation with hyperglycemia. This study will further be helpful in timely management of vitamin D deficiency associated morbidity.

\section{MATERIALS AND METHODS}

This prospective case control study was conducted in the department of medicine, Pakistan Navy Ship (PNS) Shifa Hospital Karachi from January to December 2015. A total of 302 study subjects were selected after approval of the institutional ethical committee. Out of which 151 newly diagnosed type 2 diabetes cases [on the basis of American Diabetic Association (ADA) criteria] from Medical Out Patient Department (OPD) of the Hospital were selected through non probability consecutive sampling. Age and gender matched 151 healthy subjects from general population were identified and selected as controls randomly. Newly diagnosed type $2 \mathrm{DM}$ patients and controls of both genders, between 35 to 65 years of age were included in the study. Already diagnosed old cases of DM and vitamin D deficiency on the basis of history and medical record or those under treatment for vitamin D deficiency were excluded from the study. Informed consent of included patients was taken after explaining the study protocol. All the patients were investigated for serum $25(\mathrm{OH}) \mathrm{D}_{3}$ measured by electrochemiluminescence immunoassay using Roche Elecsys $^{\circledR}$ Systems while plasma glucose and HbA1C were estimated by routine methods on Roche Hitachi ${ }^{\circledR}$ in pathology laboratory of PNS Shifa Hospital. Vitamin D deficiency was defined as serum level of $25(\mathrm{OH}) \mathrm{D}_{3}$ less than $25 \mathrm{nmol} / \mathrm{L}$ while insufficiency from 25 to $50 \mathrm{nmol} / \mathrm{L}$ and sufficiency more than $50 \mathrm{nmol} / \mathrm{L}$. The patients were declared as newly diagnosed type $2 \mathrm{DM}$ with $\mathrm{HbA} 1 \mathrm{c}$ more than $6.5 \%$ and fasting plasma glucose of more than $7 \mathrm{mmol} / \mathrm{L}$ on more than two occasions, one week apart [12].

Statistical analysis of all the data was done in statistical package for social sciences version 22 (SPSS Inc. Chicago, IL, USA). Mean and standard deviation were calculated for quantitative variables like age, plasma glucose fasting, $\mathrm{HbAlc}$ and serum $25(\mathrm{OH}) \mathrm{D}_{3}$ levels. Frequencies and percentages were calculated for qualitative variables like gender, different age groups (35 to 50,51 to 65 ) and vitamin $\mathrm{D}$ deficiency. Independent sample $\mathrm{T}$ test was applied to see vitamin $\mathrm{D}$ deficiency between cases of newly diagnosed type $2 \mathrm{DM}$ and controls of similar age groups and gender. Independent sample $\mathrm{T}$ test was applied to see significance of different age groups and gender with regard to vitamin D levels in cases of newly diagnosed type 2 DM and healthy controls separately. Pearson correlation and linear regression curve estimation between vitamin D levels and $\mathrm{HbA} 1 \mathrm{c}$ was also analyzed [P value of $<0.05$ was considered as significant (2 tailed)].

\section{RESULTS}

Out of total 302 study subjects, Vitamin D levels of $36 \pm 19$ in 151 newly diagnosed type $2 \mathrm{DM}$ cases and of $65 \pm 31$ in 151 controls of similar age groups and gender were compared. Vitamin D levels were found significantly lower in newly diagnosed type $2 \mathrm{DM}$ having $\mathrm{p}$ value $<0.001$. Frequency of vitamin $\mathrm{D}$ deficiency in newly diagnosed type $2 \mathrm{DM}$ cases was recorded in $58(38.4 \%)$, insufficiency in $61(40.4 \%)$ and $32(21.2 \%)$ were having normal levels while in healthy controls vitamin D deficiency was found in $13(8.6 \%)$, insufficiency in $53(35 \%)$ while $85(56 \%)$ were having normal levels showing $\mathrm{p}$ value of $<0.05$ (Table $\mathbf{1}$ ).

Table 1. Difference of Vitamin D Levels between Newly Diagnosed Type 2 DM Cases and Healthy Controls $(\mathrm{n}=302)$.

\begin{tabular}{|l|c|c|c|}
\hline Parameter & $\begin{array}{c}\text { DM (Cases) } \\
\text { Mean + SD } \\
(\mathbf{n}=151)\end{array}$ & $\begin{array}{c}\text { No DM } \\
\text { (Controls) } \\
\text { Mean + SD } \\
(\mathbf{n}=151)\end{array}$ & P- Value \\
\hline Age in Years & $53.7 \pm 8.7$ & $53.2 \pm 8.8$ & 0.633 \\
\hline $\begin{array}{l}\text { Plasma } \\
\text { Glucose } \\
\text { Fasting }\end{array}$ & $9.2 \pm 1.5$ & $5.1 \pm 0.7$ & 0.000 \\
\hline HbA1c & $9.4 \pm 1.4$ & $5.7 \pm 0.6$ & 0.000 \\
\hline Vitamin D Level & $36 \pm 19$ & $65 \pm 31$ & 0.000 \\
\hline $\begin{array}{l}\text { Vitamin D } \\
\text { Sufficiency }\end{array}$ & $64 \pm 16$ & $86 \pm 25$ & 0.000 \\
\hline $\begin{array}{l}\text { Vitamin D } \\
\text { Insufficiency }\end{array}$ & $37 \pm 7$ & $43 \pm 10$ & 0.001 \\
\hline $\begin{array}{l}\text { Vitamin D } \\
\text { Deficiency }\end{array}$ & $19 \pm 4$ & $22 \pm 1.6$ & 0.012 \\
\hline
\end{tabular}

Out of 302 subjects, in 151 newly diagnosed type 2 diabetes patients, 73 (48\%) were male and $78(52 \%)$ female while 56 (37\%) were between 35-50 years of age and 95 (63\%) 
between $51-65$ years, with mean age of $53.7 \pm 8.7$ years. Vitamin D deficiency with regards to age showed that out of 58 vitamin D deficient cases, 12 were between 35 - 50 years and 46 between $51-65$ years of age, revealing more deficient cases with advancing age. Significant difference was found in low vitamin D levels in different age groups both for cases and controls separately ( $\mathrm{p}$ value $<0.05$ ). With regard to gender, out of 58 cases of vitamin D deficiency 22 were male and 36 were females in newly diagnosed type $2 \mathrm{DM}$ patients. Significant difference was found in vitamin $D$ levels with regard to gender in cases ( $p$ value $<0.05$ ) but was found insignificant in healthy controls ( $\mathrm{p}$ value $>0.05$ ) (Table 2).

Table 2. Comparison of Vitamin D Levels with Regards to Gender and Age Groups Separately in Controls and Cases of Newly Diagnosed type 2 DM in PNS Shifa Hospital, Karachi $(\mathrm{n}=302)$.

\begin{tabular}{|c|c|c|c|}
\hline Parameter & n $(\%)$ & $\begin{array}{l}25(\mathrm{OH}) \mathrm{D}_{3} \\
\text { Mean } \pm \text { SD }\end{array}$ & P-Value \\
\hline \multicolumn{4}{|l|}{ CASES } \\
\hline \multicolumn{4}{|l|}{ Gender } \\
\hline Male & $73(48 \%)$ & $41 \pm 21$ & \\
\hline Female & $78(52 \%)$ & $31 \pm 14$ & \\
\hline \multicolumn{4}{|l|}{ Age Groups } \\
\hline 35-50 years & $56(37 \%)$ & $42 \pm 17$ & 0.001 \\
\hline 51-65 years & $95(63 \%)$ & $32 \pm 19$ & \\
\hline \multicolumn{4}{|l|}{ CONTROLS } \\
\hline \multicolumn{4}{|l|}{ Gender } \\
\hline Male & $73(48 \%)$ & $64 \pm 29$ & 0.734 \\
\hline Female & $78(52 \%)$ & $66 \pm 33$ & \\
\hline \multicolumn{4}{|l|}{ Age Groups } \\
\hline 35-50 years & $61(40 \%)$ & $77 \pm 30$ & \\
\hline $51-65$ years & $90(60 \%)$ & $57 \pm 30$ & 0.000 \\
\hline
\end{tabular}

Correlation between vitamin D deficiency and HbA1C was found to have inverse relationship with significant $p$ value $<$ 0.001(Fig. 1).

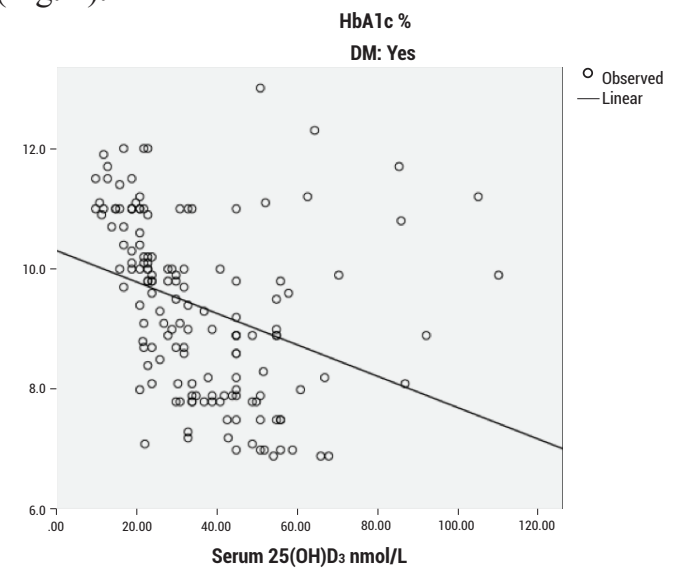

Fig. (1). Correlation between Vitamin D Deficiency and HbA1c in Newly Diagnosed Type 2 DM Patients Showing $p$ value 0.000 . $(n=151)$.

\section{DISCUSSION}

Pakistani population has high prevalence of type 2 DM [13]. Among the normal healthy individuals of different ages the prevalence of vitamin D deficiency is high [14]. The association of Vitamin D and DM has been described for more than twenty-five years now [15]. Many studies have revealed that vitamin D is related to various aspects of glucose metabolism e.g. improving beta-cell function of pancreas, insulin secretion and insulin sensitivity and its deficiency is one of the important environmental factors leading to hyperglycemia $[16,17]$.

In our study, using serum vitamin D levels of less than 25 $\mathrm{nmol} / \mathrm{L}$, vitamin D deficiency was found in $38.4 \%$ patients of newly diagnosed DM as compared to $8.6 \%$ in controls. Similarly, insufficiency $(25-50 \mathrm{nmol} / \mathrm{L})$ of vitamin D was $40.4 \%$ in cases as compared to $35 \%$ in controls. During literature search, no such case control study was found in Pakistan but results from a similar study conducted by Riyaz Ahmad Daga, et al. [18] in northern India in 2012 on newly diagnosed patients of both type 1 and type $2 \mathrm{DM}$, recorded a deficiency of $91.1 \%$ in cases as compared to $58.5 \%$ in healthy controls. Another study by Dr. G. B. Doddamani et al . in 2013 at Bagalkot town of India [19] on vitamin D status found that $70 \%$ of the newly detected type $2 \mathrm{DM}$ patients were vitamin $\mathrm{D}$ deficient $(<50 \mathrm{nmol} / \mathrm{L})$. This difference is because their cut off level for vitamin D deficiency was 50 $\mathrm{nmol} / \mathrm{L}$ while as per latest guidelines our lower cut off level was at $25 \mathrm{nmol} / \mathrm{L}$. Further splitting the results with regards to age and gender it was found that the frequency of vitamin D deficiency escalated considerably with advancing age and was more prevalent in females in cases, also found more deficiency in advancing age but similar vitamin D levels for gender in healthy controls. Possible reasons for this female preponderance can be predominantly home bound females, not seeking early medical care. Similarly, poor nutritional status, limited sun exposure and age-related decrease in cutaneous synthesis may be the cause of increased deficiency with advancing age. These findings are similarly supported by a case control study performed by Bayani MA, et al. in 2014 at a teaching hospital of northern Iran in which they recorded a deficiency of $64.2 \%$ with a cut off value of $50 \mathrm{nmol} / \mathrm{L}$ with a mean concentration of vitamin $\mathrm{D}$ being lower in women and with advancing age [20].

Another significant finding in this study was inverse relationship between vitamin $\mathrm{D}$ level and $\mathrm{HbAlc}$ and our study results are consistent with observations from a recent cross sectional study performed by Khalida Iqbal, et al. in 2016, in Karachi [21] study by Harish Kumar, et al. in 2015, by Kant, et al. in 2010 [22], another large study performed by Kositsawat $\mathrm{J}$, et al. on US population in 2010 [23] and a number of observational studies carried out in European countries $[24,25]$. The inverse relationships between Vitamin 
D level and glycemic control support an active role of vitamin $\mathrm{D}$ in pathogenesis of type $2 \mathrm{DM}$. The postulated mechanisms by which vitamin $\mathrm{D}$ could be influencing glucose metabolism in diabetic patients include: improvement in insulin sensitivity and $\beta$ cell survival, increased insulin secretion from pancreatic $\beta$ cells and regulation of calcium flux for normalization of glucose tolerance and protection of beta cells against cytokine induced apoptosis [26].

\section{LIMITATION OF THE STUDY}

Our study does not clarify exactly whether vitamin D deficiency is due to type $2 \mathrm{DM}$ or vitamin D deficiency has a role in causing hyperglycemia. To better understand the role of vitamin $\mathrm{D}$ in the development and progression of type 2 $\mathrm{DM}$, high quality randomized control trials (RCTs) are needed that may find out the exact pathogenesis of vitamin D deficiency in type $2 \mathrm{DM}$ patients.

\section{CONCLUSION}

We concluded that the frequency of vitamin D deficiency is high among patients with newly diagnosed type $2 \mathrm{DM}$ with advancing age and more common in females. The association of vitamin D deficiency with poor glycaemic control in Pakistani patients with type $2 \mathrm{DM}$ points towards the possible role of vitamin D supplementation in regulation of glycemic control in these patients. So, it is recommended that every patient who is newly diagnosed with type $2 \mathrm{DM}$ should be screened for vitamin $\mathrm{D}$ deficiency and vitamin D supplementation must be given where necessary.

\section{CONFLICT OF INTEREST}

Declared none.

\section{ACKNOWLEDGEMENTS}

Declared none.

\section{REFERENCES}

[1] First WHO Global report on diabetes. 2016; Available at: http://www.who.int/diabetes/global-report

[2] Hilger J, Friedel A, Herr R, et al. A systematic review of vitamin D status in populations worldwide. Br J Nutr 2013; 9: 1-23.

[3] Pittas AG. Systemic review: Vitamin D and cardiometabolic outcomes. Ann Intern Med 2010; 152: 307-14. DOI: 10.7326/0003-4819-152-5-201003020-00009

[4] Ye Z, Sharp SJ, Burgess S, et al. Association between circulating 25-hydroxyvitamin $\mathrm{D}$ and incident type 2 diabetes: A mendelian randomisation study. Lancet Diabetes Endocrinol 2014; 3: 35-42.

DOI: $10.1016 /$ S2213-8587(14)70184-6

[5] Kumar H, Singh VB, Meena BL, Chandra S, Single R.
Correlation of vitamin D level with glycemic control in type 2 diabetes mellitus. Sch J Appl Med Sci 2015; 3(6B): 2277-83.

[6] Ahrani AA, Ball A, Shepherd L, Rahim A, Jones AF, Bates A. The prevalence of vitamin D abnormalities in South Asians with type 2 diabetes mellitus in the UK. Int J Clin Pract 2010; 64: 351-5. DOI: 10.1111/j.1742-1241.2009.02221.x

[7] Mi-ambres I, Sánchez-Quesada JL, Vinagre I, et al. Hypovitaminosis D in type 2 diabetes:relation with features of the metabolic syndrome and glycemiccontrol. Endocr Res 2015; 40: 160-5. DOI: 10.3109/07435800.2014.982326

[8] Holick MF. Vitamin D: Importance in the prevention of cancers, type 1 diabetes, heart disease, and osteoporosis. Am J Clin Nutr 2004; 79(3): 362-71. DOI: 10.1093/ajcn/79.3.362

[9] Garland CF, Garland FC, Gorham ED, et al. The role of vitamin D in cancer prevention. Am J Public Health 2006; 96(2): 252-61. DOI: 10.2105/AJPH.2004.045260

[10] Mathieu C, Gysemans C, Giulietti A. Vitamin D and diabetes. Diabetologia 2005; 48(7): 1247-57.

DOI: $10.1007 / \mathrm{s} 00125-005-1802-7$

[11] Nyomba BL, Auwerx J, Bormans V. Pancreatic secretion in man with subclinical vitamin D deficiency. Diabetologia 1986; 29(1): 34-8. DOI: 10.1007/BF02427278

[12] American Diabetes Association. Diagnosis and classification of diabetes mellitus. Diabetes Care 2010; 33 (Suppl 1): S62-9. DOI: $10.2337 / \mathrm{dc} 10-\mathrm{S} 062$

[13] Shera AS, Jawad F, Maqsood A. Prevalence of diabetes in Pakistan. Diabetes Res Clin Pract 2007; 76: 219-22.

DOI: 10.1016/j.diabres.2006.08.011

[14] Mehboobali N, Iqbal SP, Iqbal MP. High prevalence of vitamin D deficiency and insufficiency in a low income peri-urban community in Karachi. J Pak Med Assoc 2015; 65: 946-59.

[15] Gedik O, Akalin S. Effects of vitamin D deficiency and repletion on insulin and glucagon secretion in man. Diabetologia 1986; 29: 142-45. DOI: 10.1007/BF02427083

[16] Pittas AG, Lau J, Hu FB, Dawson-Hughes B. The role of vitamin $\mathrm{D}$ and calcium in type 2 diabetes. A systematic review and metaanalysis. J Clin Endocrinol Metab 2007; 92: 2017-29. DOI: $10.1210 /$ jc. $2007-0298$

[17] Krishna SG, Bubblu T, Amarabalan R. Role of vitamin D in Diabetes. J Endocrinol Metab 2011; 1(2): 47-56.

[18] Daga RA, Laway BA, Shah ZA, et al. Vitamin D deficiency in early onset diabetes. Arq Bras Endocrinol Metab 2012; 56(7): 423-8. DOI: 10.1590/S0004-27302012000700003

[19] Doddamani GB, Boke U, Kora S, Chickmath R. Serum vitamin $\mathrm{D}$ levels in newly detected type 2 diabetes mellitus. 
Sch J Appl Med Sci 2013; 1(6): 786-88.

[20] Bayani MA, Banasaz B, Saeedi F. Status of vitamin-D in diabetic patients and compared it with healthy individuals. Caspian J Intern Med 2014; 5(1): 40-2.

[21] Iqbal K, Islam N, Mehboobali N, Asghar A, Iqbal MP. Association of vitamin D deficiency with poor glycaemic control in diabetic patients. J Pak Med Assoc 2016; 66(12):1562-65.

[22] Kant R, Chandra R, Arzumanyan H, Krug E. Prevalence of vitamin $\mathrm{D}$ deficiency and association with glycemic control in patients with type 2 diabetes mellitus: A retrospective analysis. Endocr Rev 2010; 31: 221-6.

DOI: 10.1210/endo-meetings.2010.PART1.P4.P1-164

[23] Kositsawat J, Freeman VL, Gerber BS, Geraci S. Association of A1c levels with vitamin D status in US adults: Data from the National Health and Nutrition Examination Survey. Diabetes Care 2010; 33: 1236-38. DOI: 10.2337/dc09-2150

[24] Hutchinson MS, Figenschau Y, Njølstad I, Schirmer H, Jorde R. Serum 25 hydroxyvitamin D levels are inversely associated with glycated haemoglobin $(\mathrm{HbA}(1 \mathrm{c}))$. The Tromsø Study. Scand J Clin Lab Invest 2011; 71: 399-406.

DOI: $10.3109 / 00365513.2011 .575235$

[25] Kostoglou-Athanassiou I, Athanassiou P, Gkountouvas A, Kaldrymides P. Vitamin D and glycemic control in diabetes mellitus type 2. Ther Adv Endocrinol Metab 2013; 4: 122-8. DOI: $10.1177 / 2042018813501189$

[26] Pittas AG, Lau J, Hu FB, Dawson-Hughes B. The role of vitamin Dand calcium in type 2 diabetes. A systematic review and meta analysis. J Clin Endocrinol Metab 2007; 92: 2017-29. DOI: $10.1210 /$ jc.2007-0298 